\title{
Clinical Profile of Adults with Long-Standing Type 1 Diabetes: A 30-year-Experience from Theptarin Hospital, Thailand
}

\author{
Thewjitcharoen Yotsapon, Krittiyawong Sirinate, Porramatikul Sriurai, Anuntakulnatee Tawee, \\ Kittipoom Worawit, Vongterapak Somboon, Nakasatien Soontaree, Himathongkam Thep
}

Diabetes and Thyroid Center, Theptarin Hospital, Bangkok, Thailand

\begin{abstract}
Objective. To present our 30-year experience with type 1 diabetes in adults treated at Theptarin hospital, Bangkok, Thailand.

Methodology. A retrospective study was conducted on medical records of patients with type 1 diabetes in Theptarin hospital between 1983 and 2013. Clinical characteristics, glycemic control, and complications were retrieved and compared between patients who developed complications and those who have remained free of complications.

Results. There were 129 T1DM patients who attended our hospital during the three decades. Two patients died from sepsis and leukemia. Only 70 patients are still active on follow-up (median time of follow-up 11.1 years, range 0.3-29.2 years). In the active follow-up cohort, the mean age of onset was 25.3(12.4) years and duration of diabetes was 14.4(10.0) years. The mean $\mathrm{HbA}_{1 \mathrm{c}}$ and LDL were $7.9(1.4 \%)$ and $99(30) \mathrm{mg} / \mathrm{dl}$ respectively. Optimal glycemic control $\left(\mathrm{HbA}_{1 \mathrm{c}} \leq 7 \%\right)$, LDL control (LDL $\left.\leq 100 \mathrm{mg} / \mathrm{dl}\right)$, and target blood pressure (BP $\leq 130 / 80 \mathrm{mmHg}$ ) were achieved in $31 \%$, $54 \%$, and $97 \%$ of patients respectively. The optimal combined target values for glucose, LDL, and blood pressure were achieved in only $17 \%$ of patients. The cumulative incidence of retinopathy, nephropathy, and cardiovascular disease were $17 \%, 19 \%$, and $0.4 \%$, respectively. Only longer duration of diabetes was associated with increased risk of development of microvascular complications.
\end{abstract}

Conclusions. Despite advancement in the treatment of diabetes, optimal glycemic control has not been achieved in most adult patients with T1DM. Microvascular complications have been observed in about one fifth of patients. Intensive therapy should be implemented as early as possible in order to ameliorate long-term complications of diabetes.

Keywords: Type 1 diabetes, adults, complications

\section{INTRODUCTION}

The worldwide incidence of Type 1 diabetes (T1DM), as well as the survival rate of patients with T1DM, is increasing from improved management in the past three decades. The International Diabetes Federation (IDF) Diabetes Atlas, 6th edition, estimates that worldwide, 497,100 children below 15 years of age are living with diabetes. ${ }^{1}$ This number would be greater if you added adults with T1DM who developed diabetes during childhood. Moreover, newly diagnosed adults with T1DM are also a growing population that requires attention from practicing clinicians. The key message from the Diabetes Control and Complications Trial Research Group (DCCT) indicated that the destiny of diabetic complications could be changed with intensive glycemic control. ${ }^{2}$ Therefore, at a time of dramatic increases in the prevalence of obesity, it is appropriate that type 2 diabetes has received a great deal of attention. However, it is equally important to acknowledge and address T1DM, whose prevalence is also increasing and whose management remains complex.

Thailand is one of the countries from South-East Asia with a lower prevalence of T1DM compared with European countries. ${ }^{3}$ However, according to the recent review of the diabetes burden in Thailand, ${ }^{4}$ the incidence of T1DM in children in the North-Eastern part of Thailand has increased in recent years. Unfortunately, data on adult patients with T1DM in Thailand is sparse and no longterm follow-up study is available. Therefore, our present study is aimed to describe our 30-year experience with T1DM in adults who have been treated at Theptarin hospital, which is a comprehensive diabetes center in Bangkok. Our objective was to determine clinical characteristics, glycemic control and complications in our cohort of adults with T1DM. We also examined factors which might predict microvascular complications in our cohort.
e-ISSN 2308-118X

Printed in the Philippines

Copyright $(0) 2014$ by the JAFES

Received April 9, 2014. Accepted October 20, 2014

http://dx.doi.org/10.15605/jafes.029.02.08
Corresponding author: Yotsapon Thewiitcharoen, $M D$

Theptarin Hospital, Bangkok, Thailand

3858 Rama IV Rd., Klong Toey

Bangkok 10110, Thailand

Tel. No.: 066-02-3487000

E-mail:kamijoa@hotmail.com 


\section{METHODOLOGY}

This retrospective study was approved-by the Ethics board committee of Theptarin hospital. We retrospectively reviewed the charts of all adults with T1DM (age $>15$ years old) who were treated between 1983 and 2013 at Theptarin hospital, which is one of largest diabetes centers in Bangkok with over 4,000 registered diabetic patients. T1DM was defined on the basis of abrupt onset of symptoms including polyuria, polydipsia or unexplained weight loss, diabetic ketoacidosis (DKA), absent insulin reserve as shown by $\mathrm{C}$-peptide assay $(<0.6$ $\mathrm{ng} / \mathrm{ml}$ ), and requirement of insulin from the time of diagnosis for control of hyperglycemia. If pancreatic autoantibodies were negative or unknown, then insulin must have been started at or shortly after diagnosis and used continually thereafter. Other types of diabetes including latent autoimmune diabetes in adult (LADA) were excluded. Patients who were lost to follow-up in the previous 12 months were also excluded from this study.

Demographic data, last recorded A1C and chronic complications were retrieved during the study period. The frequency of self monitoring blood glucose (SMBG) and method of insulin adjustment were also collected from medical records. In the absence of these datain the charts, telephone contact were attempted by diabetic nurse educators. Retinopathy was detected with the regular dilated eye examinations by ophthalmologists annually. Nephropathy was defined as persistent proteinuria greater than $500 \mathrm{mg} / 24$ hours or microalbuminuria greater than 30 $\mathrm{mg} / 24$ hours confirmed on at least 2 occasions, 3-6 months apart. Hypertension was defined as a blood pressure $>130 / 80 \mathrm{mmHg}$ and hypercholesterolemia was defined as an LDL cholesterol $>100 \mathrm{mg} / \mathrm{dL}$. Achieving global risk controls (ABC goals) mean an $\mathrm{A} 1 \mathrm{C} \leq 7.0 \%$, BP $\leq 130 / 80$ $\mathrm{mmHg}$, and LDL cholesterol $\leq 100 \mathrm{mg} / \mathrm{dL}$. Other comorbidities and autoimmune disorders were also collected. The diagnosis of autoimmune thyroid disorder was made on the basis of history, signs of diffuse goiter, and positive autothyroid antibodies (Anti-thyroid peroxidase and Anti-thyroglobulin).

\section{Statistical Analysis}

Continuous variables were presented as mean (SD) and categorical variables were presented as proportions. Chisquare test was used to compare the factors which were associated with microvascular complications and p-value $\leq 0.05$ was considered statistically significant. The duration period of development of complication was computed as the time of onset of diabetes up to the time at which complications are detected. For the patients who were free of complication, the duration period was computed as the time period of onset of diabetes up to the time of last follow-up. All statistical analyses were conducted using the Statistical Package for the Social Sciences (version 17.0; SPSS, Chicago, IL, USA).

\section{RESULTS}

One hundred twenty-nine T1DM patients were treated at Theptarin hospital during a 30-yr period (1983-2013). Two patients died from sepsis and leukemia. Only seventy patients $(54 \%)$ had completed the follow-up data and were enrolled in this retrospective study (median time of follow-up 11.1 years, range 0.3-29.2 years). There were 34 males $(48.5 \%)$ and 36 women $(51.5 \%)$ with a mean age of 39.5(13.3) years (range 13-76), a mean age at onset of T1DM of 25.3(12.4) years (range 5-67) and a mean duration of T1DM of 14.4(10.0) years (range 1-50). More than $80 \%$ of these patients developed T1DM at the age of more than 15 years. The body mass index (BMI) ranged from 15.6 to 29.3 $\mathrm{kg} / \mathrm{m}^{2}$ (mean at $22.5 \mathrm{~kg} / \mathrm{m}^{2}$ ) with $17.1 \%$ of patients considered to be overweight and obese (BMI over 25 $\mathrm{kg} / \mathrm{m}^{2}$ ). Pancreatic auto-antibodies and C-peptide measurements were done only in $10 \%$ of patients. The detail of baseline characteristic data was showed in Table 1.

Table 1. Baseline characteristics of adults type 1 diabetes mellitus

\begin{tabular}{ll}
\multicolumn{1}{c}{ Baseline Characteristics } & \multicolumn{1}{c}{ Active F/U(N=70) } \\
\hline Male//Female & $34(48.6 \%) / 36(51.4 \%)$ \\
Age (yrs), mean (SD) & $39.5(13.3)$ \\
Age of onset (yrs) & $25.3(12.4)$ \\
$\quad<15$ yrs & $13(18.6 \%)$ \\
$\geq 15$ yrs & $57(81.4 \%)$ \\
Disease duration (yrs) & $14.4(10.0)$ \\
$\quad \leq 5$ yrs & $13(18.6 \%)$ \\
$\quad>5-<10$ yrs & $12(17.0 \%)$ \\
$\quad \geq 10$ yrs & $45(64.4 \%)$ \\
BMI $\left(\mathrm{kg} / \mathrm{m}^{2}\right)$ & $22.5(2.8)$ \\
History of DKA & $54.3 \%$ \\
Basal bolus regimen & $68 \%$ \\
Premixed twice daily injection & $21 \%$ \\
Other regimens & $11 \%$ \\
Dose of Insulin (unit/kg/day) & $0.74(0.22)$ \\
Add-on oral hypoglycemic agents & $12.9 \%$ \\
\hline
\end{tabular}

The last visited mean A1C was 7.9 $\pm 1.4 \%$ (range $5.5-12.5 \%$ ) with $31.3 \%$ of patients having optimal glycemic control (HbA1c $\leq 7 \%$ ). LDL control (LDL $\leq 100 \mathrm{mg} / \mathrm{dl}$ ), and target blood pressure (BP $\leq 130 / 80 \mathrm{mmHg}$ ) were achieved in $54 \%$, and $97 \%$ of patients respectively. The optimal combined target values for glucose, LDL, and blood pressure (ABC goals) were achieved in only $17 \%$ of patients. When patients were classified according to the duration of diabetes, the patients who had duration between 5 and 10 years had the worst glycemic control and optimal combined target values. The detail of ABC goals were showed in Table 2.

The frequency of SMBG and method of insulin adjustment were retrieved from medical records and telephone contact in 45 patients $(64.3 \%)$. Most patients did SMBG only 1-2 times per day (36\%) and $13 \%$ of patients did not do SMBG in the past month. It is interesting that patients who did SMBG more than 4 times per day ( $9 \%$ of patients) could achieve target A1C (A1C < $\%$ ). Two patients have been admitted due to hypoglycemic coma in the previous 12 months. For insulin adjustment methods, most patients $(46 \%)$ used the dose of insulin according to the 
Table 2. The detail of $A B C$ goals in adults with type 1 diabetes mellitus

\begin{tabular}{|c|c|c|c|c|}
\hline Target Goal & $\begin{array}{l}\text { Whole Cohort } \\
(\mathrm{N}=70)\end{array}$ & $\begin{array}{c}\text { Disease duration } \\
\leq 5 \text { yrs } \\
(\mathrm{N}=13)\end{array}$ & $\begin{array}{l}\text { Disease duration } \\
>5-<10 \text { yrs } \\
(\mathrm{N}=12)\end{array}$ & $\begin{array}{c}\text { Disease duration } \\
\geq 10 \text { yrs } \\
(\mathrm{N}=45)\end{array}$ \\
\hline \multicolumn{5}{|l|}{ Glycemic Control } \\
\hline$\leq 7 \%$ & $31.3 \%$ & $38.5 \%$ & $14.3 \%$ & $34.9 \%$ \\
\hline $7.1-7.9 \%$ & $25.9 \%$ & $15.4 \%$ & $28.6 \%$ & $30.2 \%$ \\
\hline$\geq 8 \%$ & $42.8 \%$ & $46.1 \%$ & $57.1 \%$ & $34.9 \%$ \\
\hline $\begin{array}{l}\text { Optimal Blood Pressure } \\
\text { Control }(B P \leq 130 / 80 \mathrm{mmHg})\end{array}$ & $97.0 \%$ & $100.0 \%$ & $100.0 \%$ & $92.8 \%$ \\
\hline LDL cholesterol & $54.3 \%$ & $23.1 \%$ & $42.9 \%$ & $51.2 \%$ \\
\hline $101-129 \mathrm{mg} / \mathrm{dL}$ & $30.0 \%$ & $69.2 \%$ & $42.8 \%$ & $30.2 \%$ \\
\hline$\geq 130 \mathrm{mg} / \mathrm{dL}$ & $15.7 \%$ & $7.7 \%$ & $14.3 \%$ & $18.6 \%$ \\
\hline Combined three targets & $17.2 \%$ & $23.1 \%$ & $7.1 \%$ & $20.9 \%$ \\
\hline
\end{tabular}

prescription dose (fixed dose regimen). The second most common method (44\%) was to adjust insulin based on patient's preference (self-adjustment), however, only less than $5 \%$ of patients could adjust insulin based on insulin to carbohydrate ratio correctly. The detail of methods of insulin adjustment is presented in Figure 1.

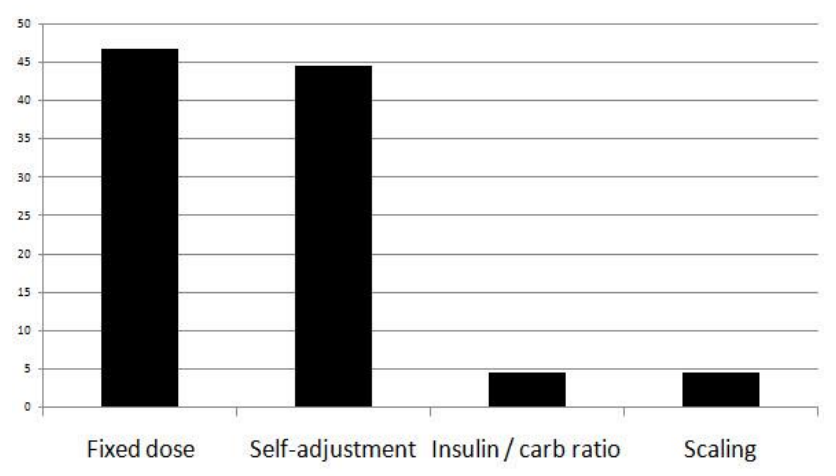

Figure 1. Percentage of insulin adjustment methods in adults type 1 diabetes mellitus

Diabetic nephropathy including microalbuminuria and chronic kidney disease developed in $12.9 \%$ and $5.7 \%$ of patients respectively. Diabetic retinopathy including nonproliferative and proliferative diabetic retinopathy developed in $8.7 \%$ and $8.7 \%$ of patients respectively. Macrovascular complications rate was $4.3 \%$ (2 cases of myocardial infarction and 1 case of ischemic stroke). Only longer duration of diabetes has been significantly associated with microvascular complications as showed in Table 3.

Table 3. Factors associated with microvascular complications in adults with type 1 diabetes mellitus, mean (SD)

\begin{tabular}{llll}
\hline \multicolumn{1}{c}{ Factors } & \multicolumn{1}{c}{$\begin{array}{c}\text { Free of } \\
\text { complication } \\
\text { group (N=52) }\end{array}$} & $\begin{array}{l}\text { Microvascular } \\
\text { complications } \\
\text { group (N=18) }\end{array}$ & p-value \\
\hline Age (years) & $39.1(13.7)$ & $40.6(12.3)$ & 0.422 \\
$\begin{array}{l}\text { Age of Onset } \\
\text { (years) }\end{array}$ & $26.8(12.3)$ & $21.0(11.9)$ & 0.620 \\
$\begin{array}{l}\text { Duration of } \\
\text { diabetes (years) }\end{array}$ & $12.6(8.7)$ & $23.1(3.2)$ & 0.025 \\
$\mathrm{BMl}\left(\mathrm{kg} / \mathrm{m}^{2}\right)$ & $22.2(2.7)$ & $23.1(3.2)$ & 0.374 \\
$\mathrm{HbA}$ (c) $^{2}(\%)$ & $7.9(1.2)$ & $7.8(1.8)$ & 0.076 \\
$\mathrm{LDL}(\mathrm{mg} / \mathrm{dl})$ & $97.8(30.6)$ & $101.6(28.1)$ & 0.247 \\
\hline & & & \\
\hline
\end{tabular}

The prevalence of autoimmune thyroid diseases in T1DM was $12.9 \%$ in the present study which consisted of 3 patients with hyperthyroid Graves' disease (4.3\%) and 6 patients with euthyroid Hashimoto's thyroiditis. No case of overt hypothyroid Hashimoto's thyroiditis was observed in this cohort study. In the group of Graves' disease, 2 patients developed Graves' disease concurrently with the onset of T1DM. Other co-morbidities included 6 patients with major depression $(8.6 \%), 1$ patient with ovarian cancer $(1.4 \%)$, and 1 patient with breast cancer $(1.4 \%)$.

\section{DISCUSSION}

Type 1 diabetes mellitus (T1DM) has traditionally been considered a disease of childhood, but more recent epidemiological studies have indicated that the incidence is comparable in adults. ${ }^{5}$ While the peak incidence of T1DM is around the time of puberty, about $25 \%$ of cases will present after 35 years of age. ${ }^{6}$ Moreover, a subset of phenotypic type 2 diabetic patients who are positive for the antibodies commonly found in type 1 diabetes which is called latent autoimmune diabetes in adults (LADA) could pose a diagnostic challenge for clinicians. ${ }^{7-8}$ Complexities arise also because of the variable definitions of LADA and T1DM. However, the recent immunologic studies showed that adults with T1DM had different antigenic differences and a more rapid decline of beta cell function after the diagnosis compared to the LADA.9-10 Therefore, only typical T1DM had been included in this study. Our data reflected the inadequate use of c-peptide and pancreatic auto-antibody testing to confirm diagnosis of T1DM. The main reason might come from economic concern of confirmation and also non-familiarity with use of these laboratory tests. Therefore, these tests should be emphasized to avoid the potential of misclassification of type of diabetes.

T1DM does not occur exclusively in children because this autoimmune disease could develop at any age. Furthermore, most patients with T1DM live until older ages due to increased survival. In this study, we observed that more than $80 \%$ of these patients developed T1DM at the age of more than 15 years and only less than $60 \%$ of patients developed diabetic ketoacidosis (DKA) at the onset of diagnosis. These findings were consistent with the 
previous study which found that the disease process seemed to have been less progressive in patients diagnosed at older ages. ${ }^{11}$ Therefore, adult issues in management of T1DM should be addressed and health care providers should be more familiar to deal with the main healthcare requirements for T1DM.

Over the past decade the tools for the management of type 1 diabetes have also evolved significantly, presenting opportunity for patients to have near-normal physiologic insulin secretion with either basal-bolus insulin therapy or continuous subcutaneous insulin infusions. The Diabetes Control and Complications Trial (DCCT) proved that the microvascular complications of T1DM could be prevented or delayed by improving glycemic control. ${ }^{2}$ Since the publication of DCCT study, the aim for therapy of individuals with type 1 diabetes has been to achieve glucose and near-normal A1C values as safely as possible. However, the DCCT and follow-up study, Epidemiology of Diabetes Interventions and Complications (EDIC) also proved a challenge to maintain normoglycemic status. Several recent studies report similar findings ${ }^{12-13}$ as in this study, with average A1C levels ranging between $8.2 \%$ and $9.0 \%$, far higher than the targets set by the American Diabetes Association. Maintenance of near-normal glucose levels is demanding, in that it requires an educated and motivated patient to coordinate the complex task of adjusting insulin doses based upon glucose levels, dietary intake, activity, illness, or stress. In real-life situations, not all people living with T1DM are motivated enough to control their glucose. As shown in Figure 1, less than 10\% of T1DM patients had adjusted insulin treatment according to carbohydrate counting as recommended in international standards. Lack of knowledge among health care workers and a deficiency of organized health care information systems are a major barrier to the delivery of quality of diabetes care in T1DM. Although psychosocial barriers such as lack of economic or social support, poor access to specialized centers, eating disorders, and other psychological problems are associated with poorer control. Support from diabetologists, diabetes educators and registered dietitians could influence the patient's attitude of their condition and subsequent self-management. ${ }^{14}$

Adults with type 1 diabetes often receive care in primary care settings rather than with an endocrinologist. Unlike the consolidated care seen in pediatric diabetes management, the lack of consolidated care in adults makes gaps in diabetes delivery in this group of patients. Moreover, diabetes care of elderly patients with T1DM is another issue that requires individualized treatment because there is increased hypoglycemia risk and functional impairment from age-related disorders ${ }^{15}$ Some older patients have multiple comorbid conditions and/or impairments of physical or cognitive functioning, while others have little comorbidity and high functional status. Life expectancy is highly variable and is defined by comorbidity and functional status more than it is by age.
Our study showed that diabetic microvascular complications have been observed in about one fifth of Thais which is similar to that reported in Caucasians. ${ }^{12}$ The natural history study, involving over 10,000 patients beginning in the early $1980 \mathrm{~s}^{16}$ found that retinopathy began to occur in T1DM patients between 3 to 5 years after diagnosis, and by 15 to 20 years, virtually all patients were affected.

There is a marked racial, ethnic and international disparity in the epidemiology of diabetic nephropathy. Diabetic nephropathy in T1DM follows a well outlined clinical course, starting with initial period of glomerular hyperfiltration associated with progressive proteinuria, followed by a gradual decline in glomerular filtration rate, eventually resulting in end-stage renal disease (ESRD). ${ }^{17}$

Nephropathy usually becomes clinically evident after 15 to 25 years of diabetes. Our results also revealed that longer duration of T1DM is a significant risk factor for diabetic microvascular complications, similar to the previous finding from North-eastern part of Thailand. ${ }^{18}$ In contrast to the DCCT, the association between HbA1c levels and complications could not be observed in this study. A possible explanation might come from the fact that the diagnosis of complications led some patients to improve their glycemic control and/ or involvement of factors others than hyperglycemia in the development of complications.

Our data revealed that patients who had disease duration between 5-10 years had the worst glycemic control ( $\mathrm{HbA}_{1 \mathrm{c}}$ $>7 \%$ ). This interesting finding might be due to less motivation for tight glycemic control or diabetes burn out. People who have burned out realize that good diabetes care is important for their health, but they just do not have the motivation to do it. In patients who had higher duration of diabetes (more than 10 years in our data) seemed to get their diabetes in range, however, diabetic complications also developed most in this group of patients. This paradoxical observation emphasized that tight glycemic control in diabetic patients needs to be implemented early. Also, we need to keep supporting patients' attitude toward the future of their long-term complications.

Obesity in T1DM which leads to insulin resistance is another issue that should be addressed because several studies confirmed that obese patients required higher dosage of insulin and were more prone to complications. ${ }^{19-20}$ In this study, almost twenty percent of patients were considered to be overweight and obese (BMI over $25 \mathrm{~kg} / \mathrm{m}^{2}$ ). Thus, the problem of obesity in T1DM should be an area of attention when treating adults with T1DM. Our findings also suggested the significance of thyroid auto-antibodies screening in T1DM as almost 10\% of patients were found to have Hashimoto's thyroiditis in euthyroid state. T1DM is frequently associated with other 
autoimmune diseases and autoimmune thyroid disease is the most common associated autoimmune disease ${ }^{21}$ so these patients should undergo antibody screening to discover undiagnosed thyroid dysfunction.

One major limitation of our study was the lack of mean A1C levels from the onset of diabetes until the time of development of complications due to the retrospective nature of our study. Therefore, last visit A1C could have been underpowered to identify the association between glycemic control and diabetic complications. Moreover, the status of pancreatic auto-antibodies and/or endogenous insulin secretory capacity was mostly unknown in our cohort. Finally, we were not able to assess the prevalence of diabetic neuropathy in our cohort due to incomplete data of neuropathy screening. However, despite these limitations, our findings demonstrated that longer duration of diabetes in this relatively large cohort of adults with T1DM is associated with diabetic microvascular complications. Longitudinal follow-up of this cohort and nationwide T1DM registry in adults will pave the way to do basic and clinical researches in our population. Moreover, qualities of life and economic burden in Thai patients who live with T1DM needed to be addressed in national policy.

In conclusion, despite advancement in the treatment of diabetes, optimal global risk factors control has not been achieved in most adult patients with T1DM. It stresses the need for patient-centered care, delivered by a multidisciplinary team. These data should stimulate a move to improve diabetes control on a national level and should include appropriate guidelines and education of social support systems.

\section{Acknowledgments}

The authors wish to thank Mr.Nirun Intarut, a biostatistician, for his assistance with the statistical analysis and the staffs of Theptarin hospital for all their support and help.

\section{Conflict of interest}

The authors declared no conflicts of interest.

\section{References}

1. International Diabetes Federation. Diabetes Atlas. 6th ed. Brussels, Belgium, International Diabetes Federation, 2013.

2. The Diabetes Control and Complications Trial Research Group. The effect of intensive treatment of diabetes on the development and progression of long-term complications in insulin-dependent diabetes mellitus. N Engl J Med. 1993; 329: 977-86. http://dx.doi.org/10.1056/NEJM199309303291401.

3. Tuchinda C, Likitmaskul S, Unachak K, Panamonta O, Patarakijavanich N, Chetthakul T. The epidemiology of type 1 diabetes in Thai children. J Med Assoc Thai. 2002; 85: 648-52.
4. Panamonta O, Thamjaroen J, Panamonta M, Panamonta N, Suesirisawat $C$. The rising incidence of type 1 diabetes in the northeastern part of Thailand. J Med Assoc Thai 2011; 94:1447-50.

5. Livingstone SJ, Looker HC, Hothersall EJ, Wild SH, Lindsay RS, Chalmers J, et al. Risk of cardiovascular disease and total mortality in adults with type 1 diabetes: Scottish registry linkage study. PLoS Med. 2012; 9: e1001321.

6. Harris MI, Robbins DC. Prevalence of adult-onset IDDM in the US population. Diabetes Care. 1994;17:1337-40. http://dx.doi.org/ 10.2337/diacare.17.11.1337.

7. Palmer JP, Hirsch IB. What's in a name: Latent autoimmune diabetes in adults, type 1.5, adult-onset, and type 1 diabetes? Diabetes Care. 2003;26:536-8. http://dx.doi.org/10.2337/ diacare.26.2.536.

8. Fourlanos S, Dotta F, Greenbaum CI, Palmer JP, Rolandsson O, Colman PG, et al. Latent autoimmune diabetes in adults (LADA) should be less latent. Diabetologia. 2005;48:2206-12. http://dx.doi.org/10.1007/s00125-005-1960-7.

9. Hampe CS, Kockum I, Landin-Olsson M, Törn C, Ortqvist E, Persson B, et al. GAD65 antibody epitope patterns of patients with Type 1.5 differ from that of type 1 diabetes patients. Diabetes Care. 2002;25:1481-1482. http://dx.doi.org/10.2337/ diacare.25.8.1481.

10. Hillman M, Torn C, Thorgeirsson H, Landin-Olsson M.IgG4-subclass of glutamic acid decarboxylase antibody is more frequent in latent autoimmune diabetes in adults than in type 1 diabetes. Diabetologia. 2004;47:1984-9. http://dx.doi.org/ 10.1007/s00125-004-1558-5.

11. Karjalainen J, Salmela P, Ilonen J, Surcel HM, Knip M. A comparison of childhood and adult type 1 diabetes mellitus. N Engl J Med. 1989; 320:881-6. http://dx.doi.org/10.1056/NEJM 198904063201401.

12. Beck RW, Tamborlane WV, Bergenstal RM, Miller KM, DuBose SN, Hall CA. T1D Exchange Clinic Network. The T1D Exchange clinic registry. J Clin Endocrinol Metab. 2012; 97: 4383-9. http://dx.doi.org/10.1210/jc.2012-1561.

13. Scottish Study Group for the Care of the Young. Factors influencing glycemic control in young people with type 1 diabetes in Scotland: A population-based study (DIABAUD2). Diabetes Care. 2001;24:239_ 244.

14. Glasgow RE, Hampson SE, Strycker LA, Ruggiero L. Personalmodel beliefs and social environmental barriers related to diabetes self-management. Diabetes Care. 1997;20:556-561. http://dx.doi.org/10.2337/diacare.20.4.556.

15. M Schutt, EM Fach, J Seufert, W Kerner, W Lang, A Zeyfang, et al. Multiple complications and frequent severe hypoglycemia in 'elderly' and 'old' patients with Type 1 diabetes. Diabet Med. 2012;29:e176-9.

16. Klein R, Klein BE, Moss SE, Cruickshanks KJ. The Wisconsin epidemiologic study of diabetic retinopathy: XVII. The 14-year incidence and progression of diabetic retinopathy and associated risk factors in type 1 diabetes. Ophthalmology. 1998;105:1801-15. http://dx.doi.org/10.1016/S0161-6420(98)91020-X.

17. Cooper ME. Pathogenesis, prevention, and treatment of diabetic nephropathy. Lancet. 1998;352:213-219. http://dx.doi.org/ 10.1016/S0140-6736(98)01346-4.

18. Panamonta N, Prathipanawatr T, Panamonta O. Factors influencing chronic diabetic complications in type 1 diabetes. Southeast Asian J Trop Med Public Health. 2012; 43: 1245-51.

19. Kilpatrick ES, Rigby AS, Atkin SL. Insulin resistance, the metabolic syndrome, and complication risk in type 1 diabetes: "Double diabetes" in the Diabetes Control and Complications Trial. Diabetes Care. 2007;30:707-12. http://dx.doi.org/10.2337/ dc06-1982.

20. McGill M, Molyneaux L, Twigg SM, Yue DK. The metabolic syndrome in type 1 diabetes: Does it exist and does it matter? J Diabetes Complications. 2008;22:18-23.

21. Kordonouri O, Klinghammer A, Lang EB, Gruters-Kieslich A, Grabert M, Holl RW. Thyroid autoimmunity in children and adolescents with type 1 diabetes: A multicenter survey. Diabetes Care. 2002;25:134650.http://dx.doi.org/10.2337/ diacare.25.8.1346.

Articles and any other material published in the JAFES represent the work of the author(s) and should not be construed to reflect the opinions of the Editors or the Publisher. Authors are required to accomplish, sign and submit scanned copies of the JAFES Declaration: that the article represents original material, that is not being considered for publication or has not been published or accepted for publication elsewhere. Consent forms, as appropriate, have been secured for the publication of information about patients; otherwise, authors declared that all means have been exhausted for securing such consent. The authors have signed disclosures that there are no financial or other relationships that might lead to a conflict of interest. All authors are required to submit Authorship Certifications that the manuscript has been read and approved by all authors, and that the requirements for authorship have been met by each author. 